\title{
The research of crystal structure and electrical properties of a new electrolyte material: Scandia and Holmia stabilized Zirconia
}

\author{
Jingchao TAO, Yong HAO* and Jun WANG ${ }^{\dagger}$ \\ State Key Laboratory of Metal Matrix Composites, Shanghai Jiao Tong University, Shanghai 200240, China \\ *Institute of Engineering Thermophysics, Chinese Academy of Science, Beijing 100190, China
}

\begin{abstract}
Weakly agglomerated nano-crystalline $\mathrm{Ho}_{2} \mathrm{O}_{3}$ and $\mathrm{Sc}_{2} \mathrm{O}_{3}$ stabilized $\mathrm{ZrO}_{2}(\mathrm{HoScSZ})$ powders are prepared by the hydrothermal method. Dense HoScSZ ceramic pellets are fabricated by isostatically pressing the powders then sintering at $1350^{\circ} \mathrm{C}$ for $2 \mathrm{~h}$. All the HoScSZ samples are cubic phase verified by $\mathrm{X}$-ray diffraction. $7 \mathrm{~mol} \% \mathrm{Sc}_{2} \mathrm{O}_{3}+1 \mathrm{~mol} \% \mathrm{Ho}_{2} \mathrm{O}_{3}$ stabilized zirconia (7Sc1HoSZ) is verified by impedance spectroscopy possessing the higher conductivity than that of 8 mol \% $\mathrm{Sc}_{2} \mathrm{O}_{3} \mathbf{s t a b i l i z e d}$ zirconia (8ScSZ). Space charge potential and specific grain boundary conductivity are calculated and fitted under the circumstance that the grain boundary is free of any amorphous phase which is verified by high resolution transmission electron microscopy. With the increase of the doping content of $\mathrm{Ho}_{2} \mathrm{O}_{3}$, the specific grain boundary conductivity and space charge potential decrease, while oxygen vacancy concentration increases.
\end{abstract}

(C2013 The Ceramic Society of Japan. All rights reserved.

Key-words : Scandia and Holmia stabilized Zirconia, Oxygen vacancy, Specific grain boundary, Space charge potential

[Received August 31, 2012; Accepted December 7, 2012]

\section{Introduction}

Solid oxide fuel cells (SOFC) possess an exceptional potential for electric power generation due to their high energy conversion efficiency and the simplicity of system design. ${ }^{1)}$ The cubic fluorite rare-earth doped $\mathrm{ZrO}_{2}$ materials are well-known candidates for the electrolyte of SOFC due to their high ionic conductivity, stability in both oxidizing and reducing environment and compatibility with electrode materials. ${ }^{2)-6)}$ Of all known rare-earth doped $\mathrm{ZrO}_{2}, \mathrm{Sc}_{2} \mathrm{O}_{3}$ stabilized $\mathrm{ZrO}_{2}$ (hereinafter describe $\mathrm{ScSZ}$ ) at around $8 \mathrm{~mol} \% \mathrm{Sc}_{2} \mathrm{O}_{3}$ content, has been shown to possess the highest oxygen ion mobility at elevated temperatures. ${ }^{7), 8)}$ However, it is difficult to stabilize the high conductivity cubic phase in the whole range of working temperature. ${ }^{8), 9)}$

Heterogeneous doping is a convenient method to improve the properties of electrolyte materials, such as increasing ionic conductivity, chemical stability and thermal stability, suppressing conductivity degradation, enhancing mechanical strength or reducing cost. The $\mathrm{Y}_{2} \mathrm{O}_{3}-\mathrm{Sc}_{2} \mathrm{O}_{3}-\mathrm{ZrO}_{2}$ system with $8 \mathrm{~mol} \%$ dopant content has been studied by Ciacchi and $\mathrm{Badwal}^{10-12)}$ and $11 \mathrm{~mol} \%$ studied by T. I. Politova. ${ }^{13)} \mathrm{Yb}_{2} \mathrm{O}_{3}$ doped $\mathrm{ScSZ}$ has been studied by Osamu Yamamoto. ${ }^{14)}$ But the conductivity of any material of those systems mentioned above is no better than $8 \mathrm{ScSZ}$. More recently, it has been studied by Man Liu ${ }^{15)}$ that $\mathrm{CeO}_{2}$ doped $\mathrm{ScSZ}$ has a higher conductivity than $8 \mathrm{ScSZ}$. However, researchers ${ }^{13)-15)}$ develop electronic conductivity at low oxygen partial pressures (about $10^{-12}$ atm at $800^{\circ} \mathrm{C}$ ) which precludes their use where such low oxygen partial pressures cannot be avoided. ${ }^{16), 17)}$ Therefore it is meaningful to search for new electrolyte systems by doping new elements into $\mathrm{ScSZ}$ to further improve the ionic conductivity. In this article, $\mathrm{Ho}_{2} \mathrm{O}_{3}$ was doped into $\mathrm{ScSZ}(\mathrm{HoScSZ})$ with different doping levels and some of those were found possessing higher ionic conductivity than that of $8 \mathrm{ScSZ}$.

\footnotetext{
Corresponding author: J. Wang; E-mail: junwang@sjtu.edu.cn
}

The key factor responsible for the ionic conductivity of $\mathrm{HoScSZ}$ is another topic discussed by researchers. First of all, crystal structure of $\mathrm{HoScSZ}$ is the foundation of conductivity. The binary system $\mathrm{Sc}_{2} \mathrm{O}_{3}-\mathrm{ZrO}_{2}$ is complex and the true equilibrium phase diagram has still not been fully resolved. Since the early work of Thornber et al., ${ }^{18)}$ at least seven phases have been identified as forming in the zirconia-rich end of the phase diagram. More recent studies have continued to refine these phase regions. ${ }^{19), 20)}$ The composition range of interest has been between 7 and $8 \mathrm{~mol} \% \quad \mathrm{Sc}_{2} \mathrm{O}_{3}$. The reason for this was to avoid the formation of any low conductivity phases, especially the monoclinic phase $\mathrm{ZrO}_{2}$ (in low dopant compositions) and rhombohedral phase (in high dopant compositions) which would have a detrimental effect. The doping of $\mathrm{Ho}_{2} \mathrm{O}_{3}$ could suppress the appearance of rhombohedral phase in $\mathrm{ScSZ}$.

Secondly, grain boundary is another factor affecting the ionic conductivity of $\mathrm{HoScSZ}$. At specific grain boundaries, i.e. the interfaces between adjacent grains, the conductivity of doped $\mathrm{ZrO}_{2}$ materials is $\sim 2$ orders of magnitude lower than the conductivity of bulk; ${ }^{18)-24)}$ this very low grain boundary conductivity is mainly attributed to the intergranular siliceous phase ${ }^{18)-22)}$ and the space charge effect. According to the core-space charge layer model, ${ }^{25)}$ a grain boundary consists of a grain boundary core (crystallographic mismatch zone) and two adjacent space charge layers. The increase of $\mathrm{Sc}^{3+}$ and $\mathrm{Ho}^{3+}$ dopants will increase the concentration of oxygen vacancies in order to keep the electro-neutrality in the lattice. The increase of oxygen vacancy concentration results in the decrease of the negative $\mathrm{O}^{2-}$ in the grain boundary space charge layers to keep the ionic defects at equilibrium on the surface. The lack of anions on the surface forms a positive charge potential in the space charge region which depletes the positive oxygen vacancies. The depletion of oxygen vacancies in the grain boundary space charge layer is mainly responsible for the low grain boundary conductivity without the effect of the siliceous phases. This was also proposed by Burggraaf et al. ${ }^{26)}$ in 1982. More recently, $\mathrm{Y}_{2} \mathrm{O}_{3}$ doped $\mathrm{ZrO}_{2}$ 
Table 1. Nomenclature, compositions and relative density of specimens examined in this study

\begin{tabular}{|c|c|c|}
\hline Nomenclature & Composition & $\begin{array}{c}\text { Relative } \\
\text { density }(\%)\end{array}$ \\
\hline 7Sc1HoSZ & $7 \mathrm{~mol} \% \mathrm{Sc}_{2} \mathrm{O}_{3}+1 \mathrm{~mol} \%$ & $96 \%$ \\
\hline 7Sc3HoSZ & $\begin{array}{l}\mathrm{Ho}_{2} \mathrm{O}_{3}+92 \mathrm{~mol} \% \mathrm{ZrO}_{2} \\
7 \mathrm{~mol} \% \mathrm{Sc}_{2} \mathrm{O}_{3}+3 \mathrm{~mol} \% \\
\mathrm{Ho}_{2} \mathrm{O}_{3}+90 \mathrm{~mol} \% \mathrm{ZrO}_{2}\end{array}$ & $97 \%$ \\
\hline 7Sc5HoSZ & $\begin{array}{l}7 \mathrm{~mol} \% \mathrm{Sc}_{2} \mathrm{O}_{3}+5 \mathrm{~mol} \% \\
\mathrm{Ho}_{2} \mathrm{O}_{3}+88 \mathrm{~mol} \% \mathrm{ZrO}_{2}\end{array}$ & $96 \%$ \\
\hline 9Sc1HoSZ & $\begin{array}{l}9 \mathrm{~mol} \% \mathrm{Sc}_{2} \mathrm{O}_{3}+1 \mathrm{~mol} \% \\
\mathrm{Ho}_{2} \mathrm{O}_{3}+90 \mathrm{~mol} \% \mathrm{ZrO}_{2}\end{array}$ & $95 \%$ \\
\hline 10Sc1HoSZ & $\begin{array}{l}10 \mathrm{~mol} \% \mathrm{Sc}_{2} \mathrm{O}_{3}+1 \mathrm{~mol} \% \\
\mathrm{Ho}_{2} \mathrm{O}_{3}+89 \mathrm{~mol} \% \mathrm{ZrO}_{2}\end{array}$ & $98 \%$ \\
\hline $11 \mathrm{Sc} 1 \mathrm{HoSZ}$ & $\begin{array}{l}11 \mathrm{~mol} \% \mathrm{Sc}_{2} \mathrm{O}_{3}+1 \mathrm{~mol} \% \\
\mathrm{Ho}_{2} \mathrm{O}_{3}+88 \mathrm{~mol} \% \mathrm{ZrO}_{2}\end{array}$ & $95 \%$ \\
\hline $8 \mathrm{ScSZ}$ & $8 \mathrm{~mol} \% \mathrm{Sc}_{2} \mathrm{O}_{3}+92 \mathrm{~mol} \% \mathrm{ZrO}_{2}$ & $97 \%$ \\
\hline
\end{tabular}

with high purity was studied, and a Schottky barrier model ${ }^{27)}$ was proposed.

In this work, $\mathrm{HoScSZ}$ samples with different $\mathrm{Sc}_{2} \mathrm{O}_{3}$ and $\mathrm{Ho}_{2} \mathrm{O}_{3}$ dopant contents were investigated. In order to prepare high purity and weakly agglomerated samples (either of which may affect the sintering property and electrical property), the hydrothermal preparation method was applied to prepare the HoScSZ powder. By comparing the impedance spectroscopy and X-ray spectroscopy of the HoScSZ samples with the different dopant $\mathrm{Sc}_{2} \mathrm{O}_{3}$ and $\mathrm{Ho}_{2} \mathrm{O}_{3}$ ratio, one can establish the correlation between the ionic conductivity and the corresponding change in the microstructure of the HoScSZ. The other objective of this work is to explore the role of $\mathrm{Ho}_{2} \mathrm{O}_{3}$ doping ratio on specific grain boundary conductivity of HoScSZ by analyzing the thickness and space charge potential of grain boundaries.

\section{Experimental}

\subsection{Preparation}

Nano-crystalline HoScSZ powders were prepared by the hydrothermal urea homogeneous precipitation method. Stoichiometric solutions of $\mathrm{ZrClO}_{2}$ (A.R.; Sinopharm Chemical Reagent Company, China), $\mathrm{ScCl}_{3}$ (99.99\% Sinopharm Chemical Reagent Company, China) and urea (AR; Sinopharm Chemical Reagent Company, China) with a cation concentration of $0.2 \mathrm{~mol}^{-1}$ in a Teflon cup $(100 \mathrm{ml})$. The cup was then transferred into a stainless steel autoclave and subjected to a hydrothermal treatment at $200^{\circ} \mathrm{C}$ for $12 \mathrm{~h}$ under autogenous pressure in an electric oven. As the autoclave cooled down to room temperature naturally, the precipitated powders were filtered, washed with deionized water and ethanol in a centrifuge, and dried in a vacuum oven at about $110^{\circ} \mathrm{C}$. The as-prepared powders were pressed isostatically into pellets with a diameter of $10-11 \mathrm{~mm}$ and thickness of $0.9-1.0 \mathrm{~mm}$ under a pressure of $50 \mathrm{MPa}$, followed by sintering under static air at $1350^{\circ} \mathrm{C}$ for $2 \mathrm{~h}$. Table 1 outlines the nomenclature, composition and relative densities (determined by Archemides method) for various specimens used in this study.

\subsection{Microstructural characterization}

The microstructure of nano-crystalline HoScSZ powders was investigated by means of transmission electron microscopy TEM (JEM 2100, 200KV, JEOL, Japan) to verify its weakly agglomerated morphology. Phase analysis was performed by X-ray diffraction using a Phillips X'Pert Pro powder diffractometer ( $\mathrm{Cu} \mathrm{KR}, 45 \mathrm{kV}, 40 \mathrm{~mA})$.
The grain size and the microstructure of the pellets were observed using scanning electron microscopy SEM (Carl Zeiss LEO $1550 \mathrm{VP}$ field emission, $3 \mathrm{kV}$ excitation voltage). The high resolution transmission electron microscopy HREM (JEM 2100, $200 \mathrm{KV}$, JEOL, Japan) was also used to observe the morphology of the grain boundaries of HoScSZ. The HREM samples were prepared by standard methods, involving mechanical grinding to a thickness of about $0.1 \mathrm{~mm}$, dimpling to about $10 \mu \mathrm{m}$, and then ion-beam milling to electron transparency.

\subsection{Impedance spectroscopy}

The conductivity of sintered pellets was measured by $\mathrm{AC}$ impedance spectroscopy in air from 300 to $450^{\circ} \mathrm{C}$ with samples equilibrated for $30 \mathrm{~min}$ at each temperature. Impedance spectra were measured every $10^{\circ} \mathrm{C}$. The measurement sequence was repeated several times until the resistance at each temperature stabilized. Data were collected in the frequency range from 0.02 $\mathrm{Hz}$ to $10^{7} \mathrm{~Hz}$ using a Solartron 1260 at a zero bias with a perturbation amplitude of $200 \mathrm{mV}$. Platinum ink (Engelhard 6082) was brushed onto both polished surfaces. The ink was applied to one side of the samples and sintered at $900^{\circ} \mathrm{C}$ for $2 \mathrm{~h}$. The identical procedure was repeated for the other side. Four-wire (2 platinum wires each side) system measurement was applied in order to minimize the inductance in the measurement configuration.

Normally, three arcs in the complex impedance spectra (Fig. 1) are observed in the high-to-low frequency sequence, corresponding to the responses of the bulk, grain boundaries and electrodes, respectively. The resulting impedance spectra were analyzed in terms of an equivalent circuit model in which (depending on the temperature regime) distinct RQ subcircuits were used to represent the bulk and grain boundary regions, where $\mathrm{R}$ is an ideal resistor with $Z_{R}=R$, and $Q$ is a constant phase element with $\mathrm{Z}_{\mathrm{Q}}=\left[\mathrm{Y}(\mathrm{j} \omega)^{\mathrm{n}}\right]^{-1}$, where $\mathrm{j}$ is imaginary unit, $\omega$ is the frequency, and $\mathrm{Y}$ and $\mathrm{n}$ are constants with $0<\mathrm{n}<1$. The capacitance, $\mathrm{C}$, of an RQ circuit was obtained from the relation $C=\mathrm{Y}^{1 / n} \mathrm{R}^{(1 / n-1)}$. The average values of $\mathrm{n}$ obtained for bulk and grain boundary subcircuits were both close to 1 (typically $\sim 0.95$ and $\sim 0.9$, respectively), as required for meaningfully determining the capacitance by this expression. The data analysis was performed using the software package Zview (Scribner Associates Inc., Southern Pines, NC).

\section{Results and discussion}

\subsection{Crystal structure and grain size}

In order to prepare high-purity HoScSZ powders with wellcontrolled compositions and microstructure, the hydrothermal homogeneous precipitation method has been employed. This approach has additional advantages of avoiding unnecessary grain growth and aggregation, each of which will severely affect the sintering density and electrical property. From the TEM image shown in Fig. 2, it was observed that the as-prepared 7Sc1HoSZ powders were an assembly of homogeneous and weakly agglomerated nano-crystals. The average particle size is about $7-8 \mathrm{~nm}$.

One of the main reasons to introduce $\mathrm{Ho}_{2} \mathrm{O}_{3}$ into $\mathrm{ScSZ}$ is to keep the high diffusion coefficient cubic phase in the range of working temperature of SOFC. As shown in Fig. 3, after carefully analyzing and comparing with the standard ICDD cards XRD pattern shows clearly that all the HoScSZ samples we studied in this article are cubic phase without any rhombohedral phase.

Figures 4 and $\mathbf{5}$ show the microstructure (grain size and density) of various $\mathrm{HoScSZ}$ specimens sintered at $1350^{\circ} \mathrm{C}$ for $2 \mathrm{~h}$. All the samples are dense without any pore or other defect. The grain size of all the samples is similar. The average grain size 


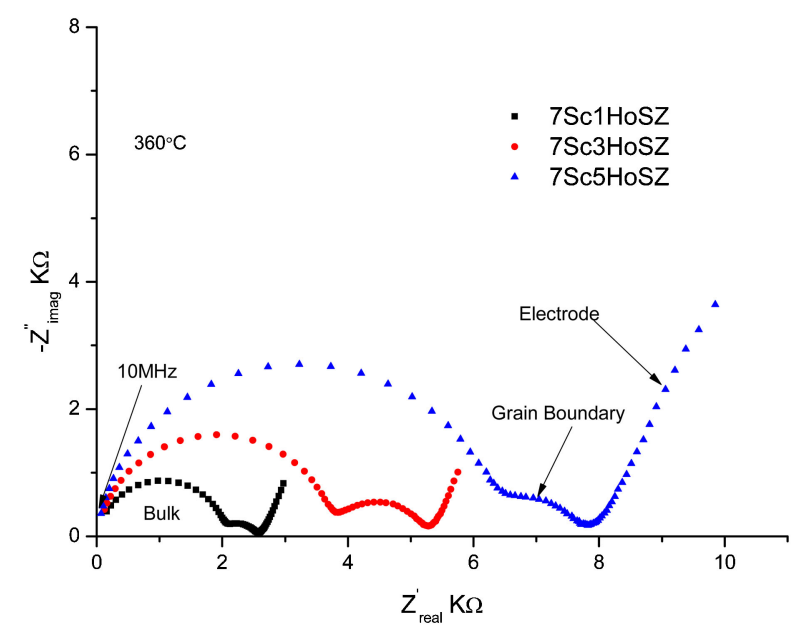

(a)

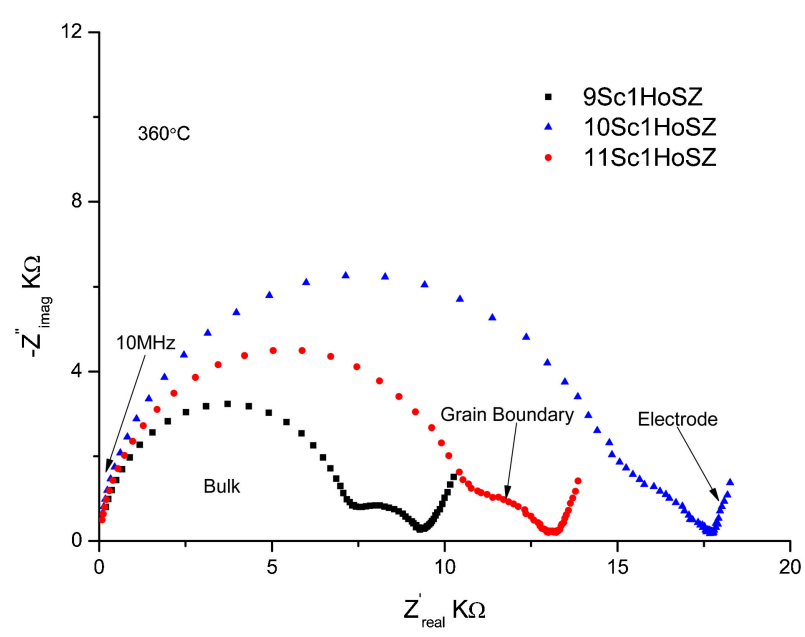

(b)

Fig. 1. (Color online) Impedance spectra at $360^{\circ} \mathrm{C}$ with different doping ratio of $\mathrm{HoScSZ}$ sintered pellets (a) same $\mathrm{Sc}_{2} \mathrm{O}_{3}$ ratio with different $\mathrm{Ho}_{2} \mathrm{O}_{3}$ doping ratio (b) same $\mathrm{Ho}_{2} \mathrm{O}_{3}$ ratio with different doping $\mathrm{Sc}_{2} \mathrm{O}_{3}$ ratio.

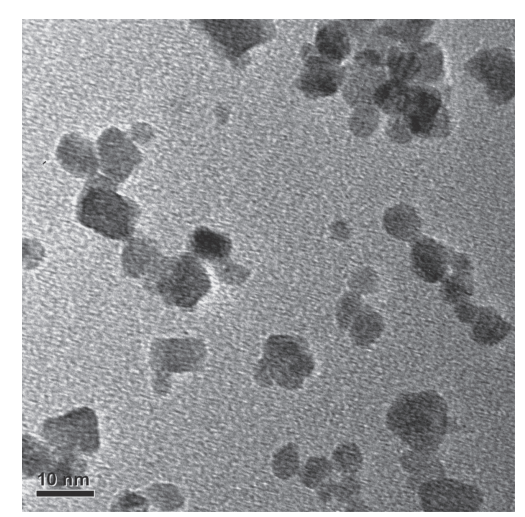

Fig. 2. TEM images of weakly agglomeration $7 \mathrm{HoScSZ}$ powder prepared by hydrothermal precipitation.

of $7 \mathrm{Sc} 5 \mathrm{HoSZ}$ is $\sim 800 \mathrm{~nm}$ which is the smallest of all the samples and $11 \mathrm{Sc} 1 \mathrm{HoSZ}$ is $\sim 1400 \mathrm{~nm}$ which is the biggest of all the samples. As is shown in Fig. 4, the increase of the doping content

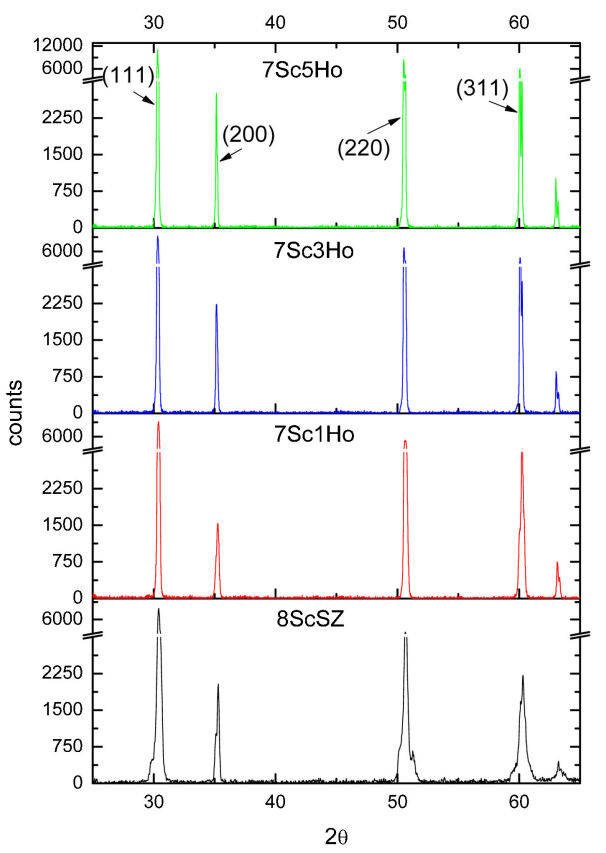

(a)

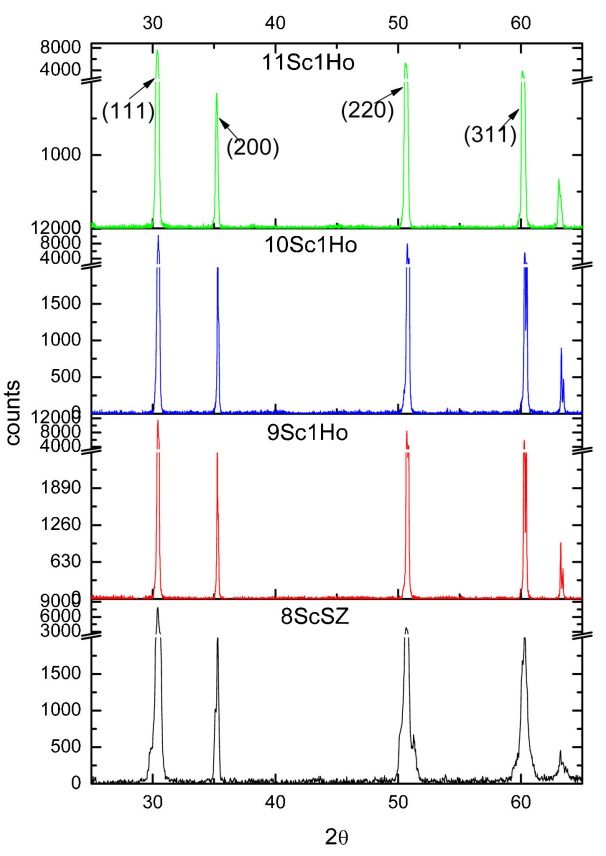

(b)

Fig. 3. (Color online) XRD pattern of different doping $\mathrm{Sc}_{2} \mathrm{O}_{3}$ and $\mathrm{Ho}_{2} \mathrm{O}_{3}$ ratio of $\mathrm{HoScSZ}$ (a) same $\mathrm{Sc}_{2} \mathrm{O}_{3}$ content with different $\mathrm{Ho}_{2} \mathrm{O}_{3}$ doping ratio (b) same $\mathrm{Ho}_{2} \mathrm{O}_{3}$ content with different $\mathrm{Sc}_{2} \mathrm{O}_{3}$ doping ratio.

of $\mathrm{Ho}_{2} \mathrm{O}_{3}$ decreases the grain size of HoScSZ slightly. On the contrary, the increase of the doping content of $\mathrm{Sc}_{2} \mathrm{O}_{3}$ increases the grain size of HoScSZ (Fig. 5).

\subsection{Total conductivity}

As discussed above, the introduction of $\mathrm{Ho}_{2} \mathrm{O}_{3}$ into $\mathrm{ScSZ}$ could suppress the appearance of rhombohedral phase which will 


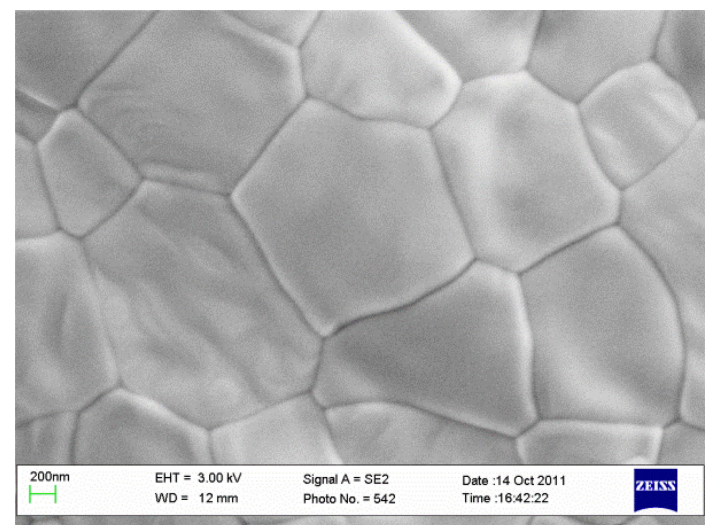

(a)

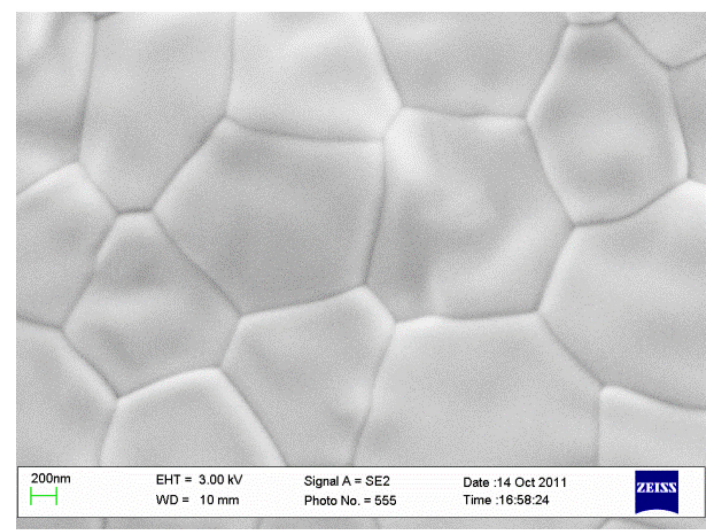

(b)

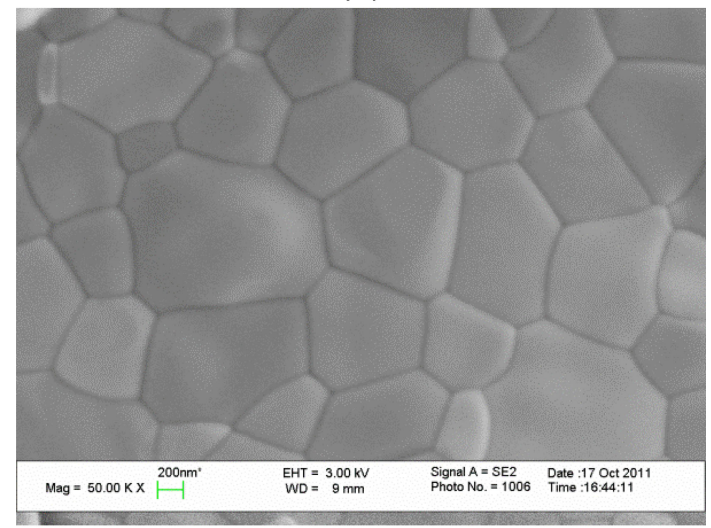

(c)

Fig. 4. (Color online) SEM images of different dopant $\mathrm{Ho}_{2} \mathrm{O}_{3}$ ratio of $\mathrm{HoScSZ}$ pellets with the same $\mathrm{Sc}_{2} \mathrm{O}_{3}$ content (a) $7 \mathrm{Sc} 1 \mathrm{HoSZ}$ (b) $7 \mathrm{Sc} 3 \mathrm{HoSZ}$ (c) $7 \mathrm{Sc} 5 \mathrm{HoSZ}$.

decrease the conductivity of ScSZ. But the $100 \%$ cubic phase HoScSZ samples show the different conductivity by doping different content of $\mathrm{Ho}_{2} \mathrm{O}_{3}$ and $\mathrm{Sc}_{2} \mathrm{O}_{3}$. As shown in Fig. 6(a), $7 \mathrm{Sc} 1 \mathrm{HoSZ}$ possesses a higher total conductivity than $8 \mathrm{ScSZ}$ under $688^{\circ} \mathrm{C}$. But the conductivity of $8 \mathrm{ScSZ}$ is higher than that of $7 \mathrm{Sc} 1 \mathrm{HoSZ}$ over $688^{\circ} \mathrm{C}$ due to the bigger activation energy which is shown in Table 2. With the increase of $\mathrm{Ho}_{2} \mathrm{O}_{3}$ doping content while fixing the content of $\mathrm{Sc}_{2} \mathrm{O}_{3}$, the total conductivity decreases. 7 $\mathrm{Sc} 3 \mathrm{HoSZ}$ also possesses the higher conductivity than $8 \mathrm{ScSZ}$ only under $405^{\circ} \mathrm{C}$. Therefore $7 \mathrm{Sc} 1 \mathrm{HoSZ}$ will be the competitive SOFC electrolyte material when the working temperature of SOFC could decrease to about $600^{\circ} \mathrm{C}$. Actually, in 2007, Fritz

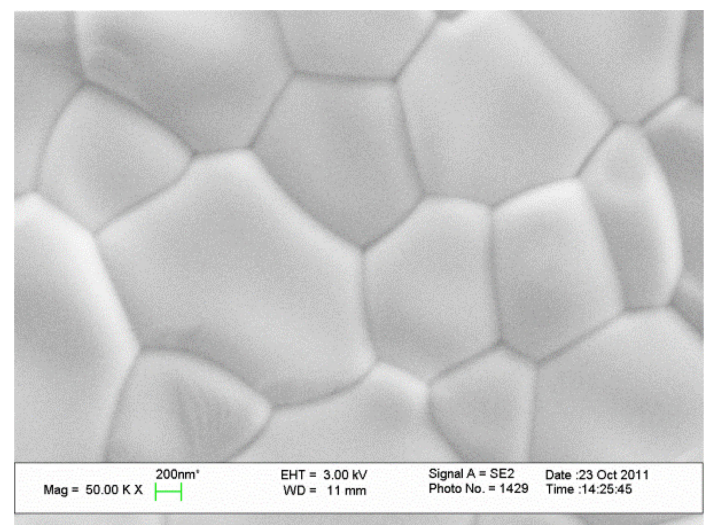

(a)

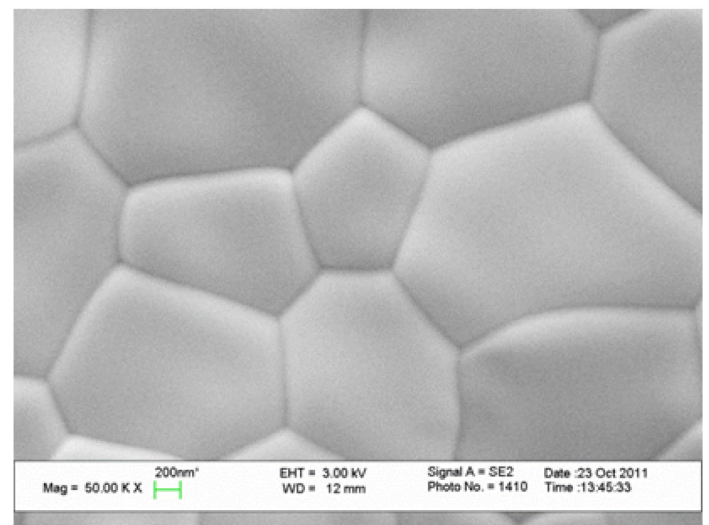

(b)

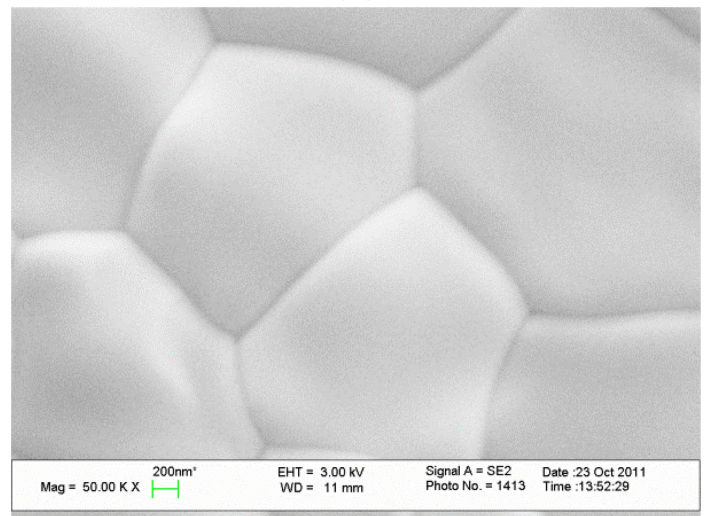

(c)

Fig. 5. (Color online) SEM images of different $\mathrm{Sc}_{2} \mathrm{O}_{3}$ dopant ratio of $\mathrm{HoScSZ}$ pellets with the same $\mathrm{Ho}_{2} \mathrm{O}_{3}$ content (a) $9 \mathrm{Sc} 1 \mathrm{HoSZ}$ (b) $10 \mathrm{Sc} 1 \mathrm{HoSZ}$ (c) $11 \mathrm{Sc} 1 \mathrm{HoSZ}$.

B. Prinz ${ }^{28)}$ fabricated a kind of ultrathin nanocrystalline yttriastabilized zirconia (YSZ) electrolyte film with the help of sputtering. Using this kind of electrolyte film the working temperature could be lowered to 350 to $400^{\circ} \mathrm{C}$. In the range of this temperature, $7 \mathrm{Sc} 1 \mathrm{Ho}$ possesses much higher conductivity than that of $8 \mathrm{ScSZ}$ compared to the temperature of $600^{\circ} \mathrm{C}$ according to Fig. 6(a). In other word, the lower the SOFC working temperature is the higer difference between $7 \mathrm{Sc} 1 \mathrm{HoSZ}$ and $8 \mathrm{ScSZ}$ the more necessity to choose $7 \mathrm{Sc} 1 \mathrm{HoSZ}$ to be the electrolyte material. Figure 6(b) shows that the increase of the doping content of $\mathrm{Sc}_{2} \mathrm{O}_{3}$ at fixed doping content of $\mathrm{Ho}_{2} \mathrm{O}_{3}$ decreases the total conductivity of HoScSZ. The total conductivity of all the 

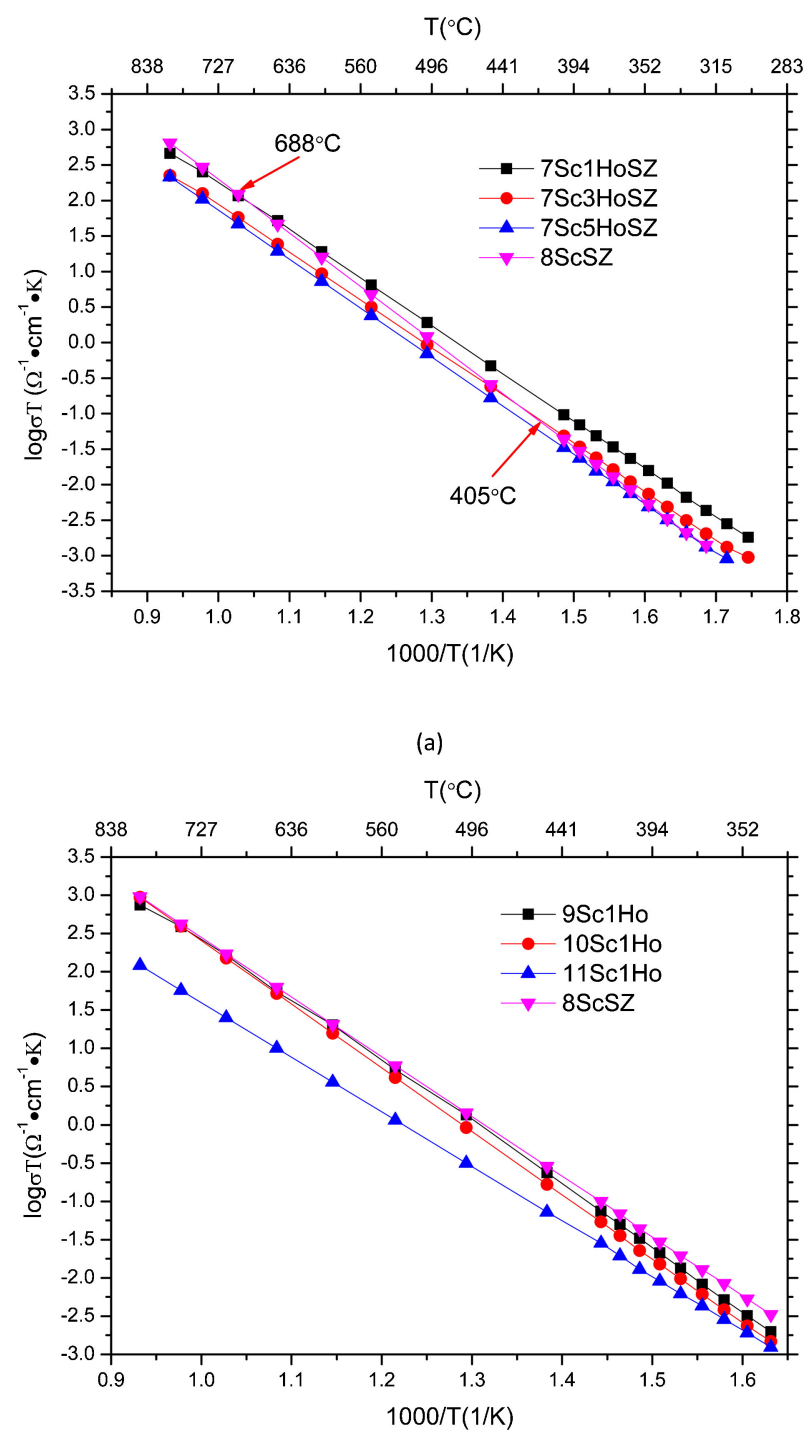

(b)

Fig. 6. (Color online) Total conductivity of different doping ratio of HoScSZ sintered pellets (a) same $\mathrm{Sc}_{2} \mathrm{O}_{3}$ ratio with different $\mathrm{Ho}_{2} \mathrm{O}_{3}$ doping ratio (b) same $\mathrm{Ho}_{2} \mathrm{O}_{3}$ ratio with different $\mathrm{Sc}_{2} \mathrm{O}_{3}$ doping ratio.

Table 2. Activation energy of HoScSZ pellets with different doping content

\begin{tabular}{lcccc}
\hline & $E_{a}^{\text {total }}(\mathrm{ev})$ & $E_{a}^{\text {bulk }}(\mathrm{ev})$ & $E_{a}^{g b}(\mathrm{ev})$ & $E_{a}^{s p, g b}(\mathrm{ev})$ \\
\hline 7Sc1HoSZ & 1.33 & 1.31 & 1.46 & 1.42 \\
7Sc3HoSZ & 1.34 & 1.31 & 1.43 & 1.39 \\
7Sc5HoSZ & 1.37 & 1.34 & 1.48 & 1.39 \\
8ScSZ & 1.60 & 1.46 & 1.45 & 1.47 \\
9Sc1HoSZ & 1.62 & & & \\
10Sc1HoSZ & 1.65 & & & \\
11Sc1HoSZ & 1.42 & & & \\
\hline
\end{tabular}

$*_{\mathrm{gb}}$ - grain boundary; sp,gb—specific grain boundary.

three samples shown in Fig. 6(b) is lower than that of $8 \mathrm{ScSZ}$. Obviously, the total conductivity of $\mathrm{HoScSZ}$ sample decreases with the increase of the doping content of $\mathrm{Sc}_{2} \mathrm{O}_{3}$ and $\mathrm{Ho}_{2} \mathrm{O}_{3}$. According to Einstein-Nernst equation [Eq. (1)], ${ }^{29)}$ the conductivity of ScSZ sample is a positive function of the concentration of carrier (in this case the oxygen vacancy), where $\sigma_{\mathrm{i}}$ is the conductivity, $\mathrm{c}_{\mathrm{i}}$ is the concentration of the carrier, $\mathrm{z}_{\mathrm{i}}$ is the charge of species, e is the electron charge, $\mathrm{K}_{\mathrm{B}}$ is Boltzmann's constant. The concentration of oxygen vacancy is a constant once the $\mathrm{Sc}_{2} \mathrm{O}_{3}$ dopant content is decided shown in Eq. (2).

$$
\begin{aligned}
& \sigma_{\mathrm{i}}=\mathrm{c}_{\mathrm{i}} \mathrm{Z}_{\mathrm{i}}^{2} \mathrm{e}^{2} \mathrm{D}_{\mathrm{i}} / \mathrm{K}_{B} \mathrm{~T}
\end{aligned}
$$

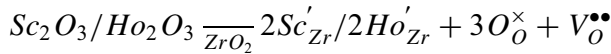

Where $S c_{Z r}^{\prime}$ and $H o_{Z r}^{\prime}$ mean that a $\mathrm{Zr}^{4+}$ site is replaced by a $\mathrm{Sc}^{3+}$ and $\mathrm{Ho}^{3+} ; O_{O}^{\times}$means that $\mathrm{O}^{2-}$ is still on its original site; $V_{O}^{\bullet \bullet}$ stands for an oxygen vacancy. The concentration of oxygen vacancy increases with the increase of doping content of $\mathrm{Sc}_{2} \mathrm{O}_{3}$ and $\mathrm{Ho}_{2} \mathrm{O}_{3}$. Therefore the conductivities of HoScSZ samples shown in Fig. 6 are not in accordance with Eq. (1). The main reason of the contradiction is association defects. ${ }^{30)}$ Due to Coulombic and elastic attractive forces between $S c_{Z r}^{\prime} / H o_{Z r}^{\prime}$ and $V_{O}^{\bullet \bullet}$ as well as the expected random distribution of $S c_{Z r}^{\prime} / H o_{Z r}^{\prime}$, the following association is likely to occur:

$$
S c_{Z r}^{\prime} / H o_{Z r}^{\prime}+V_{O}^{\bullet \bullet}=\left(S c_{Z r} / H o_{Z r} V_{O}\right)^{\prime}
$$

The association defects result in the decrease of the total conductivity of $\mathrm{HoScSZ}$ with the excessive increasing of the $\mathrm{Sc}_{2} \mathrm{O}_{3}$ and $\mathrm{Ho}_{2} \mathrm{O}_{3}$ doping content.

\subsection{Bulk and grain boundary conductivity}

The total conductivities of both $7 \mathrm{Sc} 1 \mathrm{HoSZ}$ and $7 \mathrm{Sc} 3 \mathrm{HoSZ}$ samples shown in Fig. 6(a) are higher than that of 8ScSZ. But the total conductivities of all the HoScSZ samples shown in Fig. 6(b) are lower than that of $8 \mathrm{ScSZ}$. Therefore it is indispensable for doing the further research on the samples shown in Fig. 6(b).

Because of the frequency limitations of conventional impedance meters, it is not possible to independently measure the bulk and grain boundary conductivities at high temperatures. However, one can extrapolate both bulk and grain boundary conductivities at high temperature with an Arrhenius equation, specifically [Eq. (4)]. Where $E_{a}$ is the activation energy, $A$ is pre-exponential factor determined from a fit of the data to the equation, $\mathrm{T}$ and $\mathrm{K}_{\mathrm{B}}$ are temperature and Boltzmann constant, respectively.

$$
\sigma \mathrm{T}=\mathrm{A} \exp \left(-\mathrm{E}_{\mathrm{a}} / \mathrm{K}_{\mathrm{B}} \mathrm{T}\right)
$$

Figure 7 shows the conductivity of different dopant $\mathrm{Ho}_{2} \mathrm{O}_{3}$ ratio of $\mathrm{HoScSZ}$ sintered pellets with the same $\mathrm{Sc}_{2} \mathrm{O}_{3}$ content only in the range from $300^{\circ} \mathrm{C}$ to $400^{\circ} \mathrm{C}$. As shown in Fig. $7($ a), the bulk conductivity of $7 \mathrm{Sc} 1 \mathrm{HoSZ}$ is higher than $8 \mathrm{ScSZ}$ and other samples. The bulk conductivity of $8 \mathrm{ScSZ}$ is similar to that of $7 \mathrm{Sc} 3 \mathrm{HoSZ}$ and is higher than that of $7 \mathrm{Sc} 5 \mathrm{HoSZ}$. Figure 7(b) shows that the grain boundary conductivity of $7 \mathrm{Sc} 1 \mathrm{HoSZ}$ is higher than that of $8 \mathrm{ScSZ}$, while the grain boundary conductivity of $7 \mathrm{Sc} 3 \mathrm{HoSZ}$ and $7 \mathrm{Sc} 5 \mathrm{HoSZ}$ are similar to $8 \mathrm{ScSZ}$. All the discusses above should be same at the high temperature due to the activation energies fitted by Eq. (4) are similar for both bulk and grain boundary conductivity according to Table 2 . However, the bulk conductivity activation energy of $8 \mathrm{ScSZ}$ is slightly higher than the other sample. The result shows that at rather high temperature the bulk conductivity of $8 \mathrm{ScSZ}$ will surpass that of $7 \mathrm{Sc} 1 \mathrm{HoSZ}$.

\subsection{Brick layer model and specific grain boundary conductivity}

The total grain boundary conductivity is a convolution of conductance across a single grain boundary and the number of grain boundaries within the sample. It is relatively common 


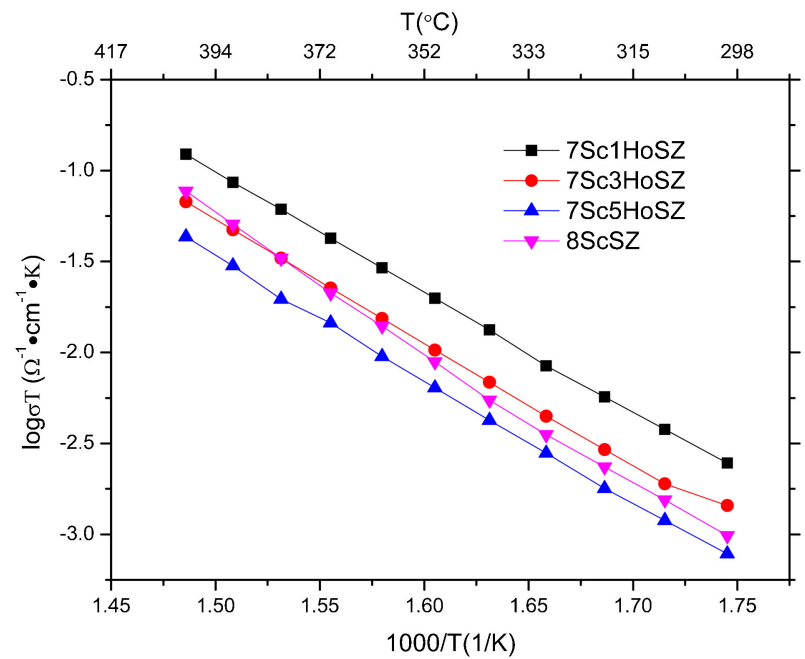

(a)

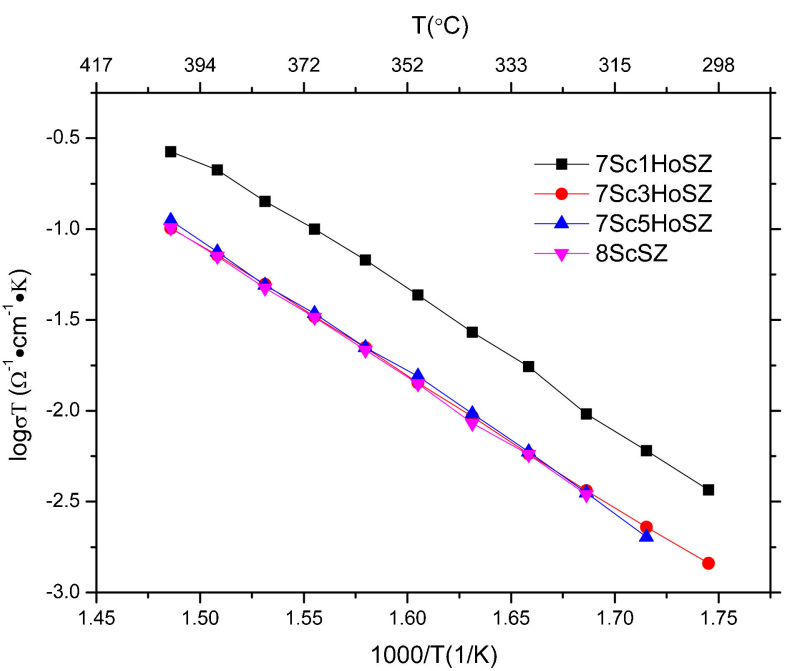

(b)

Fig. 7. (Color online) Conductivity of different doping ratio of HoScSZ sintered pellets comparing with $8 \mathrm{ScSZ}$ (a) bulk (b) grain boundary.

practice to extract from the impedance data the specific grain boundary conductivity (a real material property independent of microstructure) by making use of the "brick layer" model. ${ }^{31)}$ While that model is constructed for a particular microstructural configuration (cube-shaped grains aligned with the direction of current flow), similar results can be derived for any arbitrary geometry. Specifically, ignoring grain boundaries parallel to the direction of current flow, the total grain boundary resistance, $R_{g b}^{\text {total }}$, of a polycrystalline material is given by Eq. (5).

$$
R_{g b}^{\text {total }}=N R_{g b}^{s p}=N \rho_{g b}^{s p} \frac{\delta}{A}
$$

Where $\rho$ is resistivity, $\delta$ is the thickness of single grain boundary, $A$ is area and $\mathrm{N}$ is the number of single grain boundary and subscripts "gb" and "sp" indicate grain boundary and specific, respectively. Similarly, the capacitance of bulk and grain boundary is given by Eqs. (6) and (7), respectively, where $\varepsilon_{0}$ is the permittivity of

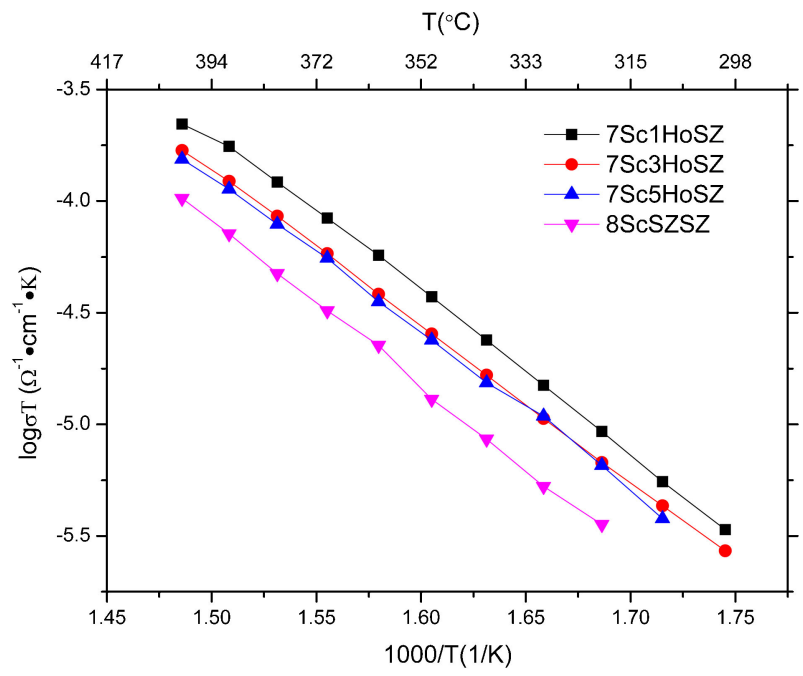

Fig. 8. (Color online) Specific grain boundary conductivity of different doping ratio of $\mathrm{HoScSZ}$ sintered pellets comparing with $8 \mathrm{ScSZ}$.

$$
\begin{aligned}
C_{b u l k} & =\varepsilon_{0} \varepsilon_{\text {bulk }} \frac{A}{L_{b u l k}} \\
C_{g b} & =\varepsilon_{0} \varepsilon_{g b} \frac{A}{L_{g b}}
\end{aligned}
$$

vacuum, $\varepsilon$ is the relative dielectric constant, and $\mathrm{L}$ is the length. For a material with moderate grain size $\mathrm{L}_{\text {bulk }}-\mathrm{L}_{\text {sample }}, \mathrm{A}_{\mathrm{gb}}-\mathrm{A}_{\text {bulk }}-$ $\mathrm{A}_{\text {sample, and }} \mathrm{L}_{\mathrm{gb}}$ is the product of the grain boundary thickness, $\delta$, and the number of grain boundary, N. It is reasonable to assume $\varepsilon_{\mathrm{gb}}-\varepsilon_{\text {bulk }}$ because the bulk and grain boundary regions are similar in both chemistry and atomic arrangement. The quantity $\mathrm{L}_{\text {sample }}$ $/ \mathrm{N}$ is the distance between 2 grain boundaries which is equivalent to the grain size of the brick layer model, $d_{g}$. Equations. (8) and (9) could be obtained by using these approximations.

$$
\begin{aligned}
& \frac{C_{\text {bulk }}}{C_{g b}}=\frac{\delta N}{L_{\text {sample }}}=\frac{\delta}{d_{g}} \\
& \frac{1}{\sigma_{g b}^{\text {total }}}=\frac{1}{\sigma_{g b}^{s p}} \frac{\delta N}{L_{\text {sample }}}
\end{aligned}
$$

Combining Eqs. (8) and (9) by using the substitution with $\sigma=$ $1 / \rho$ and $\sigma=\mathrm{L} / \mathrm{AR}$, one obtains Eq. (10).

$$
\sigma_{g b}^{s p}=\frac{C_{b u l k}}{C_{g b}} \sigma_{g b}^{\text {total }}
$$

Specific grain boundary conductivity of HoScSZ could be calculated from this analysis in which the capacitance of both bulk and grain boundary can be fitted from Fig. 1 and the total conductivity can be calculated from Fig. 6(a). As a result the conductivity of specific grain boundary of $\mathrm{HoScSZ}$ is plotted in the Arrhenius form as a function of temperature. As is shown in Fig. 8, the specific grain boundary conductivities of all the $\mathrm{HoScSZ}$ samples are higher than that of $8 \mathrm{ScSZ}$. With the increase of the $\mathrm{Ho}_{2} \mathrm{O}_{3}$ doping content the specific grain boundary conductivity increase. All the results discussed above are similar at high temperature due to the similar specific grain boundary activation energies of all the samples shown in Table 2. Therefore the introduction of $\mathrm{Ho}_{2} \mathrm{O}_{3}$ into $\mathrm{ScSZ}$ improves the "real" electrical property (specific grain boundary conductivity) of this kind of material.

\subsection{Space charge potential}

The "real" electrical property and specific grain boundary conductivity of $\mathrm{HoScSZ}$ is affected by the purity and the space 


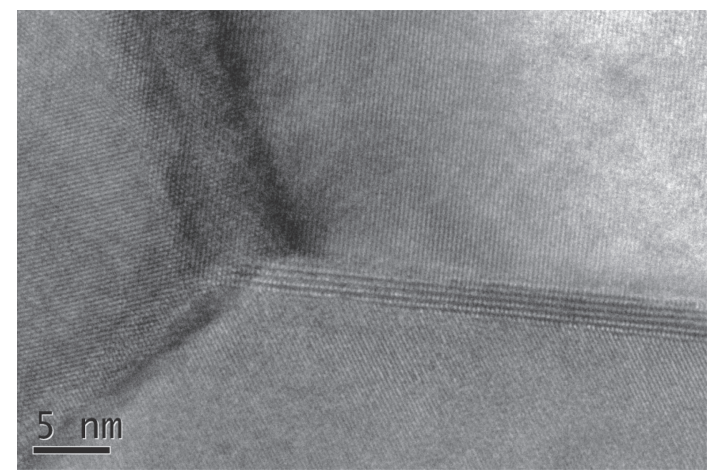

Fig. 9. HREM images of triple phase boundary of 7Ho1ScSZ.

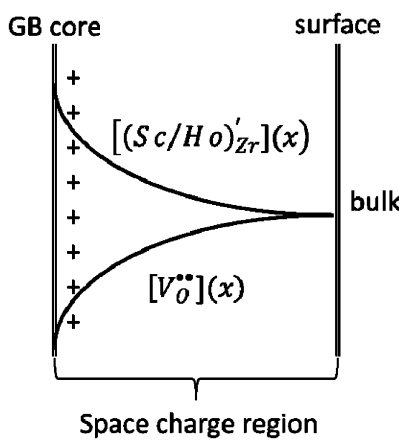

Fig. 10. Schematic of space charge potential at grain boundary.

charge potential of the grain boundary. High resolution transmission electron micrograph of $7 \mathrm{Ho} 1 \mathrm{ScSZ}$ sintered at $1350^{\circ} \mathrm{C}$ for $2 \mathrm{~h}$ is presented in Fig. 9. This micrograph, which is representative of the overall microstructure, demonstrates that the grain boundaries are free of siliceous phase and any other amorphous phases which had been demonstrated to the key factor of the decrease of the specific grain boundary of materials. ${ }^{25), 32)}$

As shown in Eq. (2), the introducing of $\mathrm{Sc} / \mathrm{Ho}^{3+}$ into $\mathrm{ZrO}_{2}$ begets the oxygen vacancy. Moreover, the concentration of oxygen vacancy is proportional to the doping content of cation. On the surface, the electrostatic balance is shown in Eq. (11). The increasing

$$
K_{\text {surf }} \rightarrow V_{O}^{\bullet \bullet}+O_{\text {surf }}^{2-}
$$

of oxygen vacancy depopulates the concentration of anion to keep the equilibration resulting in an excess positive surface charge (composed of an excess of $\mathrm{Sc} / \mathrm{Ho}^{3+}$ ). Based on this discussion, the positive space charge potential is formed as shown in Fig. 10. According to Fig. 10, under the influence of the positive charge potential the oxygen vacancy is depleted with the increasing of the distance from grain interior. While the concentration of $(\mathrm{Sc} / \mathrm{Ho})_{\mathrm{Zr}}^{\prime}$ increases with the increasing of the distance from grain interior. The grain boundary core is the middle of two neighbor grains.

According to the constancy of the electrochemical potential for mobile defects, the concentration $\mathrm{C}(x)$ of any dilute defect $\mathrm{i}$ with charge $\mathrm{Z}$ in the space charge layer is

$$
\frac{[C](x)}{[C](b u l k)}=\exp \left[-\frac{e Z_{i} \Delta \varphi(x)}{K_{B} T}\right]
$$

Where $x$ is the distance from the interface between the grain boundary core and the space charge layer, $\mathrm{C}$ is the concentration of oxygen vacancies, $\mathrm{Z}$ is 2 and e is electron charge.

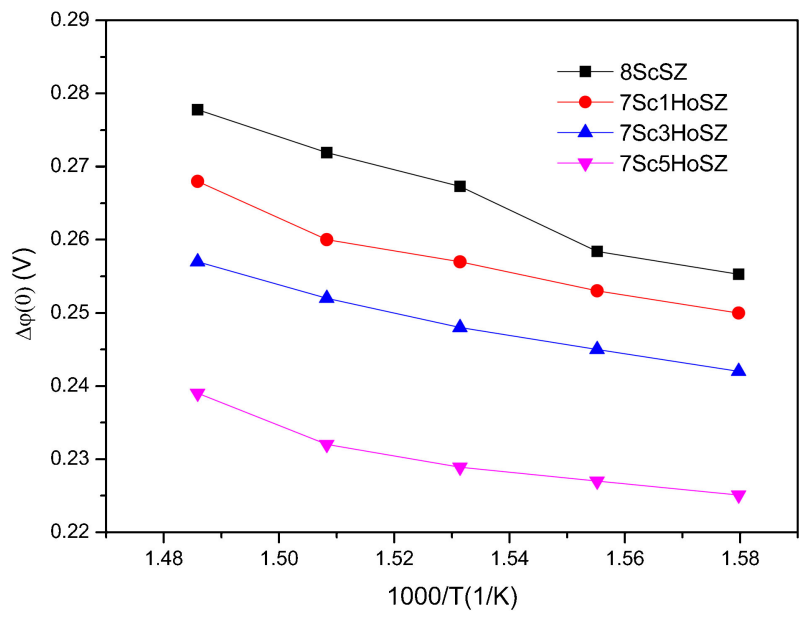

Fig. 11. (Color online) Space charge potential $\Delta \varphi(0)$ as a function of temperature of $\mathrm{HoScSZ}$ pellets with the same $\mathrm{Sc}_{2} \mathrm{O}_{3}$ composition and different $\mathrm{Ho}_{2} \mathrm{O}_{3}$ composition.

Compared with the bulk, an ideal space charge layer would have a different composition, but with the same crystal structure, and a similar conduction mechanism, so the mobility of oxygen vacancies can be assumed to be equal for the bulk and space charge layer. ${ }^{25)}$ Thus from Eq. (12) the grain boundary resistance follows that

$$
\frac{R_{g b}^{s p}}{R_{b u l k}}=\frac{\sigma_{b u l k}}{\sigma_{g b}^{s p}}=\frac{1}{\lambda_{s}} \int_{0}^{\lambda_{s}} \exp \left[\frac{e Z_{i} \Delta \varphi(x)}{K_{B} T}\right] d x
$$

Where $\lambda_{\mathrm{s}}$ is the length of space charge layer and $\Delta \varphi(x)$ is the electrostatic potential referenced to the bulk which follows that

$$
\Delta \varphi(x)=\Delta \varphi(0)\left(\frac{x-\lambda_{s}}{\lambda_{s}}\right)^{2}
$$

Combining Eqs. (13) and (14) the grain boundary space charge potential $\Delta \varphi(0)$ is related to the specific grain boundary conductivity $\sigma_{g b}^{s p}$ and the bulk conductivity $\sigma_{b u l k}$ by Eq. (15)

$$
\frac{\sigma_{b u l k}}{\sigma_{g b}^{s p}}=\frac{\exp \left[2 e \Delta \varphi(0) / K_{B} T\right]}{4 e \Delta \varphi(0) / K_{B} T}
$$

$\Delta \varphi(0)$ can be calculated from $\sigma_{\text {bulk }}$ which could be fitted from the impedance spectroscopy and $\sigma_{g b}^{s p}$ values given in Fig. 8 at different temperature; results are presented in Fig. 11: the space charge potentials of HoScSZ increases with the rise of temperature. The space charge potentials of all the HoScSZ samples are higher than that of $8 \mathrm{ScSZ}$ possessing the lowest specific grain boundary shown in Fig. 8. As shown in Fig. 11, with the increase of the doping content of $\mathrm{Ho}_{2} \mathrm{O}_{3}$, the space charge potential decreases. The decrease of positive dominating space charge potential results in the increase of the concentration of positive oxygen vacancies through the grain boundary in this case usually. Therefore the increase of the oxygen vacancies through grain boundary should increase the conductivity of the grain boundary and the total conductivity of the material. But it is true only in the case between $8 \mathrm{ScSZ}$ and $7 \mathrm{Sc} 1 \mathrm{HoSZ}$. While the conductivities of both grain boundary and total are not proportional to the space charge potential values.in the case of $7 \mathrm{Sc} 3 \mathrm{HoSZ}$ and $7 \mathrm{Sc} 5 \mathrm{HoSZ}$. That is mainly because of the association defects shown in Eq. (3). The excessive doping could induce the unexpected association defects which counteract the defect of the decrease of the space charge potential values and even decrease the grain boundary and total conductivity of the material. 
Table 3. Capacitances for bulk and grain boundary at different temperature and thickness of grain boundary of $7 \mathrm{Sc} 1 \mathrm{HoSZ}$ sintered at $1350^{\circ} \mathrm{C}$ for $2 \mathrm{~h}$ of which the grain size is $1000 \mathrm{~nm}$

\begin{tabular}{ccccc}
\hline $\begin{array}{c}\text { Temperature } \\
\left({ }^{\circ} \mathrm{C}\right)\end{array}$ & $\begin{array}{c}\mathrm{C}_{\text {bulk }} \\
(\mathrm{F})\end{array}$ & $\begin{array}{c}\mathrm{C}_{\mathrm{gb}} \\
(\mathrm{F})\end{array}$ & $\begin{array}{c}\mathrm{C}_{\mathrm{b}} / \mathrm{C}_{\mathrm{gb}} \delta_{\mathrm{gb}} \\
(\mathrm{nm})\end{array}$ & \\
\hline 300 & $2.06 \mathrm{E}-10$ & $2.10 \mathrm{E}-07$ & $9.82 \mathrm{E}-04$ & $9.82 \mathrm{E}-01$ \\
310 & $2.11 \mathrm{E}-10$ & $2.11 \mathrm{E}-07$ & $1.00 \mathrm{E}-03$ & $1.00 \mathrm{E}+00$ \\
320 & $2.30 \mathrm{E}-10$ & $2.29 \mathrm{E}-07$ & $1.00 \mathrm{E}-03$ & $1.00 \mathrm{E}+00$ \\
330 & $2.53 \mathrm{E}-10$ & $2.52 \mathrm{E}-07$ & $1.00 \mathrm{E}-03$ & $1.00 \mathrm{E}+00$ \\
340 & $2.82 \mathrm{E}-10$ & $2.84 \mathrm{E}-07$ & $9.93 \mathrm{E}-04$ & $9.93 \mathrm{E}-01$ \\
350 & $3.19 \mathrm{E}-10$ & $3.19 \mathrm{E}-07$ & $1.00 \mathrm{E}-03$ & $1.00 \mathrm{E}+00$ \\
360 & $3.61 \mathrm{E}-10$ & $3.69 \mathrm{E}-07$ & $9.77 \mathrm{E}-04$ & $9.77 \mathrm{E}-01$ \\
370 & $4.18 \mathrm{E}-10$ & $4.12 \mathrm{E}-07$ & $1.01 \mathrm{E}-03$ & $1.01 \mathrm{E}+00$ \\
380 & $4.78 \mathrm{E}-10$ & $4.76 \mathrm{E}-07$ & $1.00 \mathrm{E}-03$ & $1.00 \mathrm{E}+00$ \\
390 & $5.86 \mathrm{E}-10$ & $5.83 \mathrm{E}-07$ & $1.00 \mathrm{E}-03$ & $1.00 \mathrm{E}+00$ \\
& & & & $\sim 0.997($ average $)$ \\
\hline
\end{tabular}

To keep the equilibrium of the concentration of oxygen vacancies and the concentration of $\mathrm{O}^{2-}$ on the surface and space charge layer of HoScSZ, the positive oxygen vacancies are depleted in this region due to the lack of negative charges. The depletion which was proposed as the cause of the "intrinsic" grain boundary effect ${ }^{25}$ is described by combining Eqs. (12) and (14) as Eq. (16).

$$
\frac{\left[V_{O}^{\bullet \bullet}\right](x)}{\left[V_{O}^{\bullet \bullet}\right](\text { bulk })}= \begin{cases}\exp \left[-\frac{2 e \Delta \varphi(0)}{K_{B} T}\left(\frac{x-\lambda_{s}}{\lambda_{s}}\right)^{2}\right], & \left(x \leq \lambda_{s}\right) \\ 1, & \left(x>\lambda_{s}\right)\end{cases}
$$

Where $\left[V_{O}^{\bullet \bullet}\right](x)$ is the oxygen vacancy concentration and $\lambda_{s}$ is the thickness of the space charge layer which can be estimated as one half of the grain boundary thickness, $\delta_{\mathrm{gb} .}{ }^{31)} \delta_{\mathrm{gb}}$ could be calculated from the capacitances according to Eq. (8). Table 3 shows the fitting result of capacitances of $7 \mathrm{Sc} 1 \mathrm{HoSZ}$ sintered for $2 \mathrm{~h}$ at different temperatures. The grain boundary thickness of $7 \mathrm{Sc} 3 \mathrm{HoSZ}, 7 \mathrm{Sc} 5 \mathrm{HoSZ}$ and $8 \mathrm{ScSZ}$ samples was calculated in the same way. The average value of grain boundary thickness $\delta_{\mathrm{gb}}$ is about $0.99,0.80$ and $1.03 \mathrm{~nm}$ for $7 \mathrm{Sc} 3 \mathrm{HoSZ}, 7 \mathrm{Sc} 5 \mathrm{HoSZ}$ and $8 \mathrm{ScSZ}$ samples, respectively. Thus the grain boundary thicknesses of all the samples are similar. The fitted grain boundary size is the average value of all the grain boundary size. This kind of size is different from the size showed in Fig. 9 because we select the TEM image of wider grain boundary sample in order to show that there are no amorphous phases on the grain boundary. The oxygen vacancies concentration profile of $\mathrm{HoScSZ}$ compared with $8 \mathrm{ScSZ}$ is shown in Fig. 12: the oxygen vacancies concentration in the grain boundary space charge region increases with the increase of the doping content of $\mathrm{Ho}_{2} \mathrm{O}_{3}$.

\section{Conclusions}

1. The introduction of $\mathrm{Ho}_{2} \mathrm{O}_{3}$ into $\mathrm{ScSZ}$ (forming $\mathrm{HoScSZ}$ material) could suppress the appearance of rhombohedral phase which is detrimental to the ionic conductivity of HoScSZ.

2. $7 \mathrm{Sc} 1 \mathrm{HoSZ}$ which substitutes $1 \mathrm{~mol} \% \mathrm{Sc}_{2} \mathrm{O}_{3}$ by $1 \mathrm{~mol} \%$ $\mathrm{Ho}_{2} \mathrm{O}_{3}$ in $8 \mathrm{ScSZ}$ possesses a higher total conductivity than that of $8 \mathrm{ScSZ}$. With the increase of the doping content of $\mathrm{Ho}_{2} \mathrm{O}_{3}$ the total conductivity decreases. With the increase of the doping content of $\mathrm{Sc}_{2} \mathrm{O}_{3}$ for $7 \mathrm{Sc} 1 \mathrm{HoSZ}$ the total conductivity also decreases.

3. $8 \mathrm{ScSZ}$ possesses the lowest specific grain boundary conductivity, highest space charge potential and lowest

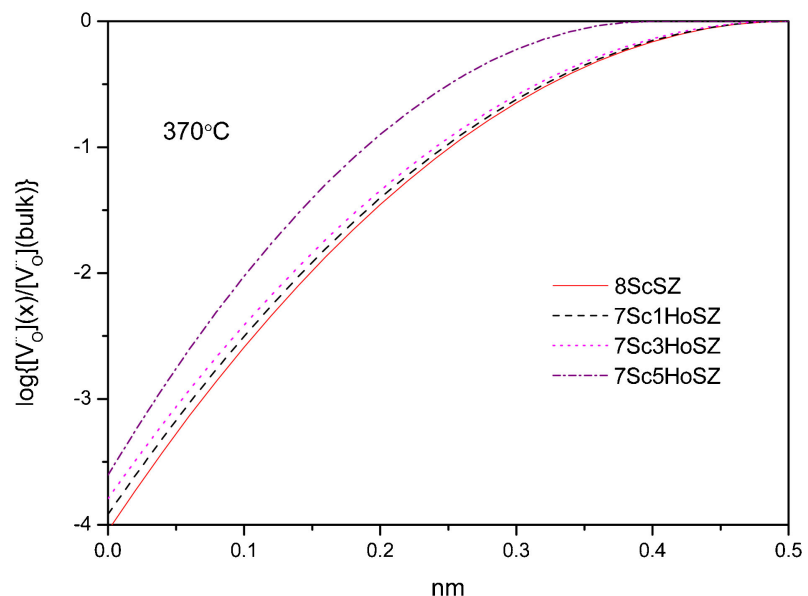

Fig. 12. (Color online) Oxygen vacancy data in the space charge regions of $\mathrm{HoScSZ}$ with different doping ratio.

oxygen vacancy concentration on the grain boundary compared to the samples of $7 \mathrm{Sc} 1 \mathrm{HoSZ}, 7 \mathrm{Sc} 3 \mathrm{HoSZ}$ and $7 \mathrm{Sc} 5 \mathrm{HoSZ}$. With the increase of the doping content of $\mathrm{Ho}_{2} \mathrm{O}_{3}$ the specific grain boundary conductivity goes down, space charge potential goes down and oxygen vacancy concentration goes up.

\section{References}

1) B. C. H. Steele, "Ceramic Electrochemical Reactors", Ceram ionic, London (1987).

2) R. Chiba, T. Ishii and F. Yoshimura, Solid State Ionics, 91, 249-256 (1996).

3) W. Huang, P. Shuk, M. Greenblatt, M. Croft, F. Chen and M. Liu, J. Electrochem. Soc., 147, 4196-4202 (2000).

4) J. Drennan and G. Auchterlonie, Solid State Ionics, 134, 75-87 (2000).

5) A. J. McEvoy, Solid State Ionics, 132, 159-165 (2000).

6) N. Q. Minh, "Science and Technology of Ceramic Fuel Cells", Elsevier, Amsterdam (1995).

7) S. P. S. Badwal, J. Mater. Sci., 22, 4125-4132 (1987).

8) F. M. Spiridonov, L. N. Popova and R. Ya. Popil'skii, J. Solid State Chem., 2, 430-438 (1970).

9) M. Yashima, M. Kakihana and M. Yoshimura, Solid State Ionics, 86-88, 1131-1149 (1996).

10) F. T. Ciacchi and S. P. S. Badwal, J. Eur. Ceram. Soc., 7, 185195 (1991).

11) F. T. Ciacchi and S. P. S. Badwal, J. Eur. Ceram. Soc., 7, 197206 (1991).

12) S. P. S. Badwal, F. T. Ciacchi, S. Rajendran and J. Drennan, Solid State Ionics, 109, 167-186 (1998).

13) T. I. Politova and J. T. S. Irvine, Solid State Ionics, 168, 153165 (2004).

14) O. Yamamoto, Y. Arati, Y. Takeda, N. Imanishi, Y. Mizutani, M. Kawai and Y. Nakamura, Solid State Ionics, 79, 137-142 (1995).

15) M. Liu, C. He, J. Wang, W. G. Wang and Z. Wang, J. Alloys Compd., 502, 319-323 (2010).

16) S. P. S. Badwal, in: U. Bossel (Ed.), Proceedings of the First The conductivity of a range of materials in the Bullet European Solid Oxide Fuel Cells Forum, J. Kinzel, Gottingen, Germany (1994) p. 399.

17) S. P. S. Badwal and K. Foger, Mater. Forum, 21, 183-187 (1997).

18) S. P. S. Badwal, F. T. Ciacchi, M. V. Swain and V. Zelizko, J. Am. Ceram. Soc., 73, 2505-2507 (1990).

19) S. P. S. Badwal and A. E. Hughes, J. Eur. Ceram. Soc., 10, 
115-122 (1992).

20) S. P. S. Badwal and S. Rajendran, Solid State Ionics, 70-71, 83-95 (1994).

21) S. P. S. Badwal, Solid State Ionics, 76, 67-80 (1995).

22) M. Gödickemeier, B. Michel, A. Orliukas, P. Bohac, K. Sasaki, L. Gauckler, H. Heinrich, P. Schwander, G. Kostorz, H. Hofmann and O. Frei, J. Mater. Res., 9, 1228-1240 (1994).

23) M. Aoki, Y.-M. Chiang, I. Kosacki, J. R. Lee, H. L. Tuller and Y.-P. Liu, J. Am. Ceram. Soc., 79, 1169-1180 (1996).

24) Y. Arachi, H. Sakai, O. Yamamoto, Y. Takeda and N. Imanishai, Solid State Ionics, 121, 133-139 (1999).

25) J. Maier, Ber. Bunsenges. Phys. Chem, 90, 26-33 (1986).

26) M. J. Verkerk, B. J. Middelhuis and A. J. Burggraaf, Solid State
Ionics, 6, 159-170 (1982).

27) X. Guo and J. Maier, J. Electrochem. Soc., 148, E121-E126 (2001).

28) H. Huang, M. Nakamura, P. Su, R. Fasching, Y. Saito and F. B. Prinz, J. Electrochem. Soc., 154, B20-B24 (2007).

29) Y. M. Chiang, D. P. Birnie, and W. D. Kingery, "Physical Ceramics: Principles of Ceramic Science and Engineering", John Wiley and Sons, New York (1997) pp. 208-211.

30) G. Xu, Y.-W. Zhang, C.-S. Liao and C.-H. Yan, Solid State Ionics, 166, 391-396 (2004).

31) S. M. Haile, D. L. West and J. J. Campbell, Mater. Res., 13, 1576-1595 (1998).

32) X. Guo and Z. Zhang, Acta Mater., 51, 2539-2547 (2003). 